\title{
REPRESENTAÇÃO E TRAÇO \\ MNÊMICO NO TEXTO FREUDIANO \\ SOBRE AS AFASIAS
}

\section{Representation and Mnemonic Trace in the Freudian Text on Aphasias}

Carlota Ibertis ${ }^{1}$

\section{Resumo}

No texto sobre as afasias, Freud introduz a discussão acerca da abordagem mais adequada para o estudo da mente contrapondo à visão localizacionista estrita, inspirada em Meynert, a hipótese funcionalista baseada em $\mathrm{H}$. Jackson. Isso envolve uma reflexão acerca da natureza dos fenômenos mentais que o autor estaria elaborando. Com efeito, uma passagem do mencionado texto descreve o traço mnêmico desde o ponto de vista do paralelismo psicofísico enquanto que em outro, 0 conceito de representação é desenvolvido em uma perspectiva exclusivamente psicológica. O propósito deste trabalho é explicitar 0 tratamento dado por Freud a ambos os conceitos, evidenciando a função argumentativa no debate epistemológico-metodológico proposto pelo autor.

Palavras-chave: Traço mnêmico; Representação; Funcionalismo; Paralelismo psicofísico; Abordagem psicológica.

Doutoranda pela UNICAMP, Professora da UNIFRA. Rua das Andradas 1222, Santa Maria, RS.

E-mail: carlotam@terra.com.br

Revista de Filosofia, Curitiba, v. 17 n.20, p. 11-23, jan./jun. 2005. 
Abstract

In his text on aphasias, Freud introduces a discussion about the most suitable approach to the study of the mind, contrasting Meynert's strict localizacionist vision with the functionalistic hypothesis based on Jackson' work. This discussion entails a reflection about the nature of mental phenomena. One passage of the above mentioned textdescribes a mnemonic trace from the perspective of psycho-physic parallelism, while in another passage the concept of representation is discussed from an exclusive psychological viewpoint. This paper aims to explore Freud's treatment of these concepts, as evidence for the argumentative function of the epistemological and methodological polemic proposed by the author.

Keywords: Mnemonic trace; Representation; Functionalism; Psychophysic parallelism; Psychological approach.

O propósito deste trabalho ${ }^{2}$ é examinar a argumentação em torno de dois conceitos presentes em Sobre a concepção da afasia (Zür Auffassung der Aphasien), o de representação e o de traço mnêmico, com a intenção de evidenciar o que parecem ser duas preocupações diferentes, senão divergentes no texto. Com efeito, entre o tratamento dado ao conceito de traço mnêmico e o dado ao de representação, há diferenças epistemológicas e metodológicas a serem consideradas.

O tema da obra é, justamente, uma consideração sobre as afasias, cujo estudo, na época, estava dominado pela perspectiva localizacionista de Lichteim e Wernicke à qual Freud vai se opor. Logo no início, ele explicita as hipóteses que irá questionar: a primeira refere-se à distinção entre as afasias causadas pela destruição dos centros e as causadas pela destruição das conexões entre os centros. A segunda visa a relação topográfica entre os centros individuais da linguagem. O localizacionismo, alvo da crítica deste texto, defendia a restrição das funções nervosas a áreas anatômicas definíveis. Contra essa noção e a favor de uma perspectiva funcionalista que não descarta a localização anatômica, é que Freud vai estruturar a sua concepção sobre as afasias.

2 O presente trabalho surgiu das discussões do Grupo de Leitura Cronológica de Freud coordenado por Conceição Beltrão Fleig e Tâmara Steren dos Santos, assim como se beneficiou dos comentários de Fátima Siqueira Caropreso e Richard Theisen Simanke. Agradecemos também as contribuições em geral do parecerista desse artigo e, em especial, a indicação do texto de Theodor Lipps. 
Os primeiros quatro capítulos apresentam um exame minucioso das concepções de Wernicke, Lichteim e Grashey. No capítulo quinto, Freud aborda as noções neurológicas de Meynert que inspiram a teoria de Wernicke e Lichteim sobre um aparelho de linguagem constituído por centros no córtex, em cujas células estariam armazenadas as imagens das palavras. Separados entre si por espaço cortical sem função, os centros da linguagem estariam ligados por conduções.

Com base na crítica ao modelo anterior, Freud propõe uma área de linguagem ${ }^{3}$ na qual não mais se reconhecem centros, mas pontos nodais de entrecruzamento de vias de conexão sem hiatos funcionais. De modo que os centros postulados por Wernicke passam a ser explicados por áreas corticais receptivas e motoras adjacentes e pelos feixes de fibras cruzados. Resultado disso a distinção entre afasias centrais e de condução deixa de valer, pois todos os distúrbios de linguagem originar-se-iam na interrupção das associações, isto é, das conduções.

Da argumentação de Freud contra tal concepção, nos interessa aqui a objeção a Wernicke quando sustenta que as sensações simples estariam localizadas nas terminações centrais dos nervos sensoriais.

Visto a tendência de períodos anteriores da história da medicina a localizar faculdades mentais na sua totalidade, tal como as define a terminologia psicológica, em certas áreas do cérebro, teve necessariamente de parecer um grande progresso quando Wernicke declarou que somente os elementos psíquicos mais simples, é dizer, as diferentes percepções sensoriais, podiam ser localizadas no córtex (...) Porém, não se comete, em princípio, um mesmo erro tanto quando se tenta localizar um conceito complicado como toda uma faculdade ou um elemento psíquico? (FREUD, 1973, p. 69).

Inspirado em Hughlings Jackson, Freud afirma a necessidade de distinguir entre processos fisiológicos e psíquicos. Em nota de rodapé, Freud cita Jackson denunciando a falácia de transformar nas explicações os estados físicos dos centros inferiores em estados psíquicos nos superiores. Um pouco mais adiante ele afirma:

3 Segundo Forrester essa seria uma das contribuições mais significativas de Freud para 0 estudo das afasias.

Revista de Filosofia, Curitiba, v. 17 n.20, p. 11-23, jan./jun. 2005. 
A relação entre a cadeia de sucessos fisiológicos que se dão no sistema nervoso e os processos mentais provavelmente não seja de causa e efeito. Aqueles não cessam quando estes começam; tendem a continuar, mas, a partir de certo momento, um fenômeno mental corresponde a cada parte da cadeia ou a várias partes. $\mathrm{O}$ processo psíquico é, portanto, paralelo ao fisiológico, 'um concomitante dependente (FREUD, 1973, p. 70).

Com efeito, tratar-se-iam de dois tipos de processos diferentes, paralelos entre os quais não caberia estabelecer relações de causa e efeito. Afirmar que uma idéia ou representação está localizada na célula nervosa resulta, segundo Freud, da confusão entre o fisiológico, pouco conhecido, e o psicológico, mais conhecido para a época. As modificações fisiológicas são um tipo de fenômeno diferente das idéias, mas que por desconhecimento das primeiras acabar-se-ia atribuindo características das segundas. Essa situação, na opinião de Freud, daria lugar a uma inferência sem nenhum fundamento: como as idéias simples são elementares e reconhecíveis, então as modificações fisiológicas concomitantes teriam de ser localizáveis.

No que tange ao parágrafo citado, precisamos salientar alguns pontos. Em primeiro lugar, Freud fala em cadeia de sucessos fisiológicos do sistema nervoso, ou seja, não se refere a processos isolados, mas ao sistema nervoso como um todo. Em segundo lugar, entre tal cadeia e os processos mentais não haveria relação causal, uma vez que isso suporia, por um lado, que aos eventos fisiológicos lhe seguiriam os mentais como seus efeitos. Porém, os primeiros não cessam quando começam os segundos; ao contrário, há uma certa coexistência entre eles identificada como concomitância dependente dos processos psíquicos em relação aos físicos. Pelo outro, existe a dificuldade de postular relações causais entre fenômenos de natureza completamente diversa.

Logo a seguir, Freud introduz a questão do traço mnêmico perguntando-se pelo correlato fisiológico da idéia que surge pela primeira vez ou daquela que volta a surgir. Tal correlato é caracterizado possuindo caráter processual, ou seja, não-estático e localizável. Começando em um ponto específico do córtex se estende por todo ele e ao longo de certas vias:

Quando esse fato teve lugar, deixa trás de si uma modificação, com a possibilidade de uma lembrança, na parte do córtex afetado. É muito 
duvidoso que esse sucesso fisiológico esteja associado de algum modo com algo psíquico. Nossa consciência não contém nada que, desde 0 ponto de vista psicológico, possa justificar o termo "imagem latente da lembrança". No entanto, cada vez que o mesmo estado cortical volta a ser suscitado, o sucesso psíquico anterior surge novamente como lembrança (1973, p. 71).

O que aqui queremos observar é a breve descrição de traço mnêmico, muito próxima do que no Projeto será a formulação do conceito de facilitação. Todavia, o parágrafo pretende ser uma aplicação do princípio de distinção entre processos fisiológicos e psicológicos, mas com uma relação de concomitância.

Strachey $^{4}$ vai além, sugerindo que Freud sustentaria aqui um tipo de paralelismo psicofísico. Contudo, por um lado, se paralelismo psicofísico quer dizer duas substâncias, ou seja, se essa posição supõe compromisso com um dualismo ontológico ${ }^{5}$ então ela não parece condizente nem com a esperança sempre enunciada acerca de um dia a psicanálise vir a ser substituída por tratamentos químicos; nem com a tentativa do Projeto de escrever uma psicologia em termos neurológicos. Com efeito, a crença na existência de dois tipos de realidades heterogêneas e, portanto, específicas e irredutíveis entre si, não teria razão em sustentar a confiança e, menos ainda, a expectativa da explicação, própria de uma das substâncias, primar sobre a da outra.

Pelo outro, a tese do paralelismo derivada do dualismo de substância implica em que não há qualquer relação causal entre uma substância e a outra, aspecto que, ao contrário, parece sugerido na expressão concomitante dependente. Pois, que significa senão a dependência nesse caso? O mental como concomitante dependente indica prioridade ontológica dos processos físicos, como seria o caso de uma posição epifenomenalista, onde o dualismo não é referido a substância, mas a propriedades dela. Com efeito, essa teoria entende que os fenômenos

4 Um dos apêndices, que Strachey acrescenta ao artigo sobre O Inconsciente, reproduz esses parágrafos do texto sobre a afasia intitulando-os "O paralelismo psicofísico", $\mathrm{AE}$ XIV, p. 204-206.

5 No que segue tomamos como referência a sistematização de Paul Churchland, "O problema ontológico (o problema mente-corpo)", na sua obra Matéria e consciência: uma introdução contemporânea à filosofia da mente, trad. Maria Clara Cescato, São Paulo, UNESP, 2004.

Revista de Filosofia, Curitiba, v. 17 n.20, p. 11-23, jan./jun. 2005. 
mentais são causados pela atividade cerebral. (CHURCHLAND, 2004, p. 31). Para esta variante e outras similares de dualismo, não haveria incompatibilidade com a substituição da psicanálise por uma terapia química, nem com o Projeto.

No que concerne à concepção freudiana de mente e sua relação com o corpo, não existe acordo. Sobre a citação anterior à última, mas em relação ao mesmo ponto, Nagel comenta que:

em lugar de uma alternância e interação entre processos físicos inconscientes e processos mentais conscientes, [trata-se de] um sistema causal completo, no qual, no entanto, alguns processos têm também a propriedade de consciência, ou têm concomitantes conscientes. $\mathrm{O}$ mental aparece, então, como o efeito de certo tipo de processo físico (2000, p. 26.).

Em outras palavras, segundo Nagel, Freud pensaria que tanto os processos conscientes como os inconscientes são físicos, ainda que por enquanto apenas pensáveis na sua manifestação mental. De forma semelhante, ainda que não igual, Solomon (1976, p. 63-4) indica que não existe correlação um a um entre acontecimentos mentais e físicos, antes bem, tratar-se-ia de uma equivalência funcional postulada por Freud entre sistema nervoso e (o que no futuro será) aparelho psíquico.

Voltando ao traço mnêmico, ele consiste em um processo localizável, mas em um sentido não estrito uma vez que embora comece em um ponto específico se difunde por todo o córtex. Toda vez que esse estado cerebral é ativado, surge o mesmo estado mental.

A localização dos correlatos fisiológicos da percepção e da associação é, portanto, idêntica, e como a localização de uma percepção não significa outra coisa que a localização de seu correlato, é impossível para nós contar com uma localização separada para cada um deles (FREUD, 1973, p. 72).

Não há localização da percepção, mas sim do seu correlato, assim como não localização da associação, mas do seu comelato - o mesmo da percepção. Podemos ler esse parágrafo como uma tentativa de sistematizar o imperativo jacksoniano de distinção de ordens explicativas.

Trata-se, para Freud, nos parece, de um problema metodológico antes do que de uma questão ontológica. Segundo Klimovsky, optar

Revista de Filosofia, Curitiba, v. 17 n.20, p. 11-23, jan./jun. 2005. 
pelo dualismo metodológico não obriga a um compromisso ontológico determinado. Assim, se Freud sustenta uma posição ontológica monista, como a sugerida por Nagel, então, o fisiológico e o psíquico poderiam ser concebidos como duas maneiras diferentes de olhar o mesmo (KLMOVSKY, 1995, p.313-314).

Um texto de 1897 de Theodor Lipps, O conceito de inconsciente na psicologia ${ }^{6}$, evidencia a pertinência para a época dessa discussão metodológica em torno da psicologia concordando com a distinção entre ontológico ou metafísico, por uma parte, e metodológico, pela outra: "Aquilo que pertence a esse encadeamento e que, nessa medida, é psíquico pode muito bem, ao mesmo tempo, pertencer a um encadeamento fisiológico e, desse modo, ser fisiológico" (LPPS, 2001, p.352).

Um pouco mais adiante o autor acrescenta: “[...] a psicologia é uma ciência empírica e, como tal, não lhe é permitido fazer hipóteses metafísicas. Ora, aquela identificação \{do psíquico com o fisiológico\} é uma questão metafísica que ultrapassa a experiência” (LPPS, 2001, p.353).

Lipps não descarta o monismo ontológico, simplesmente não se manifesta a respeito por considerar que não há elementos científicos para isso. Loparic ${ }^{7}$ observa que esse filósofo é mencionado pela primeira vez por Freud em uma carta a Fliess de agosto de 1898 salientando o papel do mesmo na transformação científica freudiana. Embora em 1891 ainda não tivesse contato com Lipps, é notável o acordo entre eles na preocupação metodológico-teórica acerca da distinção entre o fisiológico e o psicológico desde a qual Freud argumenta contra os pressupostos localizacionistas. Reflexão metodológica que se encontra em pleno processo de elaboração já no texto acerca das afasias e que contribuiria com a criação da psicanálise.

A psicofisiologia de nossos dias caminha, completa e necessariamente, nos rastos da psicologia. As assim chamadas explicações fisiológicas de fenômenos psíquicos são a tradução do conhecimento psicológico, efetivo ou suposto, da linguagem da psicologia para a linguagem da fisiologia do cérebro. Não há, em sentido próprio, uma psicologia fisiológica, ou seja, uma visão do encadeamento e da conformi-

6 Texto traduzido por Zeljko Loparic publicado em Natureza Humana, v. 3, n. 2, jul./ dez., 2001.

7 LOPARIC, Zeljko, Theodor Lipps: uma fonte esquecida do paradigma freudiano, Natureza Humana, v. 3, n. 2, p. 315-331, jul./dez. 2001.

Revista de Filosofia, Curitiba, v. 17 n.20, p. 11-23, jan./jun. 2005. 
dade a leis dos processos psíquicos, que seria alcançada, em primeiro lugar, no campo da fisiologia (LPPS, 2001, p. 355).

Na citação ecoam, sem dúvidas, as inquietações freudianas acerca da distinção e traducibilidade entre fisiologia e psicologia, presentes no texto que estamos examinando, mas que também se pode pensar levaram Freud à empreitada intelectual do Projeto. Curiosamente o texto sobre as afasias preanuncia a mudança metodológica após o Projeto. De forma mais taxativa, Monzani defende a continuidade desde 1891 dos princípios e orientações teóricas nas obras publicadas, considerando 0 Projeto uma ruptura dela. (1989, p.136-137).

Ora, o capítulo VI, centrado no exame da palavra, unidade funcional da linguagem, desenvolve uma perspectiva diferente da do capítulo anterior. Virada, essa, que para o leitor desavisado pode dar a impressão do abandono dos pressupostos anteriores. Antes bem, parece ser muito mais uma opção metodológica conseqüência das restrições científico-tecnológicas da época que vínhamos apontando. A respeito, Mill defendia um tempo antes:

Existe uma ciência do Espírito [psicologia] distinta e separada porque a ordem dos fenômenos mentais deve ser estudada nesses fenômenos e não inferidos de leis de fenômenos mais gerais. Sem dúvida, não se deve perder de vista as relações dessa ciência com a fisiologia. Leis do espírito podem ser leis derivadas de leis da vida animal. Mas por outra parte, negar-se as fontes e recursos da análise psicológica e pretender edificar a teoria do espírito exclusivamente nos dados que atualmente fornece a fisiologia é um grande erro (2002, L.IV, p.22).

A afirmação de Mill sobre a continuidade entre leis do espírito e as leis da vida animal merece um destaque especial. $O$ autor não nega que a natureza última de uns fenômenos e outros seja a mesma. O que ele reivindica, assim como Lipps, é a necessidade de uma abordagem própria.

Considerações fisiológicas de lado, Freud elabora os conceitos de palavra e de representação para inferir deles uma classificação nova das afasias em termos de distúrbios associativos. Com efeito, a associação, enquanto processo psíquico, é a chave para definirmos tais conceitos. Desse modo, a palavra é descrita como um complexo construído com base em um intrincado processo de associações visuais, acústicas e 
cinestésicas. Ela adquire significado quando associada ao objeto que nomeia. Emprestado de Mill, o conceito de objeto também se caracteriza por ser um complexo de associações de imagens visuais, táteis, auditivas, cinestésicas e outras.

Freud menciona a concepção de Mill acerca do objeto ser, justamente, o conjunto de qualidades transmitidas pelos sentidos (2002, p.7). Com base nisso, Freud passa da noção de palavra à de representação complexa ao estabelecer a sua referência extralingüística sustentando uma concepção denotativa da linguagem semelhante à de Mill $^{8}$ e derivada do conceito de objeto desse último (2002, p.32). Se o objeto não é senão o conjunto das suas qualidades, não existindo nada como a coisa em si, então, a palavra ao se associar com o complexo de imagens do objeto, está se associando ao objeto propriamente dito. Em outros termos, o objeto, - entendido como o conjunto das sensações que desperta - é referido pela palavra à qual se encontra ligado (MILL, 2002, p.31).

Uma vez apresentada a sua noção de representação, Freud detalha pormenorizadamente a aprendizagem da fala, da leitura e da escrita. Em primeiro lugar, associamos uma imagem sonora da palavra com a imagem da inervação da palavra. A imagem sonora da palavra falada inicialmente não coincide com a imagem sonora da palavra ouvida. Depois, adequamos nossa imagem sonora produzida com a imagem sonora que serviu de estímulo, quando aprendemos a repetir. Em terceiro lugar, aprendemos a soletrar associando imagens visuais das letras com novas imagens sonoras que nos evocam sons já conhecidos. A seguir, aprendemos a ler conectando reciprocamente uma sucessão de imagens de inervação da palavra e impressões cinestésicas da palavra percebidas ao enunciar individualmente as letras. Surgem novas imagens cinestésicas que pelas suas imagens sonoras correspondentes, as reconhecemos como já familiares. Anexamos às imagens sonoras soletradas os significados

${ }^{8}$ Quanto à referência dos nomes, Mill contrapõe duas concepções: ou bem eles são nomes das idéias que temos sobre as coisas, ou bem, eles nomeiam as coisas. Esta última é a tese defendida por ele: "Quando eu digo: "O sol é a causa do dia" não entendo que minha idéia do sol causa ou excita em mim a idéia do dia, ou, em outros termos, que pensar acerca do sol me faz pensar acerca do dia. Entendo que um certo fato físico, chamado presença do sol (que, em última análise, se resolve em sensações e não em idéias) causa um outro fato físico chamado do dia." [...] "É necessário considerar uma palavra como o Nome [...] da coisa sobre a qual queremos, pela intermediação da palavra, dar informações." (MLL, 2002, p. 32)

Revista de Filosofia, Curitiba, v. 17 n.20, p. 11-23, jan./jun. 2005. 
dos sons reconhecidos e começamos a ler com compreensão. Por último, aprendemos a escrever reproduzindo as imagens visuais das letras com ajuda das imagens cinestésicas da mão. A escrita é comparativamente mais simples e menos vulnerável do que a leitura.

Por que a descrição detalhada da aprendizagem? Qual é o seu papel na articulação do pensamento? Parece-nos que ela fornece razões, primeiro para sustentar a tese acerca do processo associativo da linguagem, segundo para defender o primado da imagem sonora na organização do complexo de palavra e, terceiro, para estabelecer a dimensão diacrônica das organizações associativas. Em relação ao processo associativo, com certeza explicitar como aprendemos a falar, ler e escrever evidencia de forma muito clara o entremeado de associações em jogo em cada uma dessas atividades.

Quanto à imagem sonora, Freud defende o seu primado na organização da função lingüística argumentando que é por meio dessa imagem, justamente, que começamos nossa aprendizagem. Ao contrário, Charcot $^{9}$ nega que haja uma regra geral de preferência em relação às formas de associação. Todos os elementos teriam direitos funcionais iguais, dependeria da organização individual decidir qual fator seria central para coordenar os outros. Como observa Osmyr Faria Gabbi Jr., se assim fosse, não teríamos nenhuma regularidade para pensar a questão da afasia, o que seria uma forte objeção para a classificação proposta por Freud (PRADO JR, 1991). Baseada na noção de representação, ela determina três formas de afasia: verbal, assimbólica e agnósica, segundo quais associações sejam afetadas, as da palavra, as da união da palavra com o objeto ou as do objeto. Se não há um padrão no procedimento associativo, não se pode fundar nele uma classificação. E tal padrão determinase pela maneira de apreendermos o uso da linguagem.

No que tange à diacronia, a aprendizagem dar-se-ia segundo estágios associativos de crescente complexidade até dominar fala, leitura e escrita. Essa sorte de princípio evolutivo permitirá explicar os distúrbios da linguagem como "retrogressão funcional" nos termos de Jackson. As diferentes atividades da linguagem realizam-se por meio das mesmas associações pelas quais as aprendemos. Nos casos de deterioro orgânico que atinge a totalidade do aparelho de linguagem, então podemos supor que se volta a uma forma primitiva de associação. Por exemplo, na afasia

${ }^{9}$ CHARCOT, Novas Lições, 1886, apud FREUD, 1973, p.110. 
motora voltamos ao estágio no qual ainda não apreendemos suficientemente a pronunciar os sons ouvidos.

Isso significa que no curso da aprendizagem se estabelecem configurações associativas que vão sucedendo-se, mas que, no entanto, não desaparecem ao serem substituídas por outras mais novas. Ao contrário, tais configurações representam estágios nos quais os mais recentes supõem os mais antigos que permanecem disponíveis, caso necessário. Em outras palavras, a afasia é uma patologia que desintegra a unidade complexa da palavra constituída por seus quatro componentes fundamentais (a imagem sonora, a imagem visual da letra, as imagens glossocinestésicas e quirocinestésicas) retornando a um dos estágios anteriores à aquisição definitiva da linguagem.

Em suma, a elaboração do conceito de representação junto à descrição detalhada do aprender os diversos aspectos da linguagem não seria nem casual, nem uma modificação da sua concepção acerca da natureza do seu objeto, senão uma tentativa de encontrar uma alternativa metodológica que não esbarrasse com as dificuldades do modelo das ciências naturais. Como sabemos, essa busca não termina com esse texto e irá continuar até encontrar a perspectiva própria no Capítulo VII da Interpretação dos Sonhos.

Resumindo o examinado, enquanto no capítulo cinco a discussão gira em torno de se as sensações ou representações simples são localizáveis e a necessidade da distinção das ordens fisiológica e psicológica; no capítulo seis, o termo representação alude, sobretudo à palavra e não tanto à sensação elementar. No cinco, Freud exemplifica a diferenciação entre o fisiológico e psicológico, com o conceito de traço mnêmico enquanto correlato fisiológico da percepção-associação e serve para argumentar contra a existência de centros de linguagem separados entre si e conectados apenas por conduções. Ao contrário, no seis, quando Freud fala em representação, abandona a preocupação pelo correlato neurológico. Nessa mudança, a aprendizagem entra em cena para substituir a fundamentação fisiológica pela psicológica. Dito de outra maneira, a aprendizagem e sua dimensão diacrônica cumprem o papel explicativo-argumentativo exercido antes pela fisiologia.

A mudança de ponto de vista do capítulo cinco para o capítulo seis poderia ser interpretada como a substituição de uma certa concepção em favor de outra. No entanto, como acima mencionado, nos parece que se trata, no pensamento de Freud, do mesmo fenômeno abordado

Revista de Filosofia, Curitiba, v. 17 n.20, p. 11-23, jan./jun. 2005. 
nas suas duas formas possíveis: como se fossem duas línguas diferentes para falar do mesmo. Em ambas, o que ele enfatiza é a perspectiva funcionalista e a consideração de cada um dos sistemas, o nervoso e o psíquico, como todos unitários. Portanto, a opção mentalista obedeceria às razões por ele mesmo aludidas acerca da falta maior de conhecimentos no campo das explicações neurofisiológicas do que no das psicológicas.

Enfim, a diacronia introduz uma série de questões em torno ao modo em que se armazenam as representações. Nesse tópico convergem, em nossa opinião, linhas de pensamento que convivem em estado germinal no interior do texto sobre as afasias. Uma delas remite ao conceito de traço mnêmico reelaborado no Projeto em uma continuação da tentativa neurofisiológica. Outra pensa a representação segundo uma análise, na qual a identificação entre processo psíquico e fisiológico é substituída por uma abordagem psicológica que terá seu desenvolvimento paradigmático no capítulo VII da Interpretação.

No que diz respeito à organização das representações em estratos de menor a maior complexidade e o papel da memória assim estruturada, nos parece que há uma continuidade entre o texto sobre a afasia, a Carta 52 e os Estudos sobre histeria.

\section{Referências}

CHURCHLAND, Paul M. Matéria e consciência: uma introdução contemporânea à filosofia da mente. Tradução de Maria Clara Cescato. São Paulo, SP: Editora da UNESP. 2004.

FORRESTER, John. A linguagem e as origens da Psicanálise. Rio de Janeiro, RJ: Imago, 1983.

FREUD, S. La Afasia. Buenos Aires: Nueva Visión, 1973.

GABBI JR, Osmyr Faria. Sobre a concepção da afasia e da histeria: notas sobre a relação entre anatomia e linguagem nos primórdios da teoria freudiana. In: PRADO JR, Bento. Filosofia da Psicanálise. São Paulo, SP: Brasiliense, 1991.

LIPPS, Theodor. O conceito de inconsciente na psicologia. Tradutor Zeljko Loparic. Natureza Humana: Revista Internacional de filosofia e práticas psicoterápicas, v. 3, n. 2, jul./dez. 2001. 
LOPARIC, Zeljko. Theodor Lipps: uma fonte esquecida do paradigma freudiano. Natureza Humana: Revista Internacional de filosofia e práticas psicoterápicas, v. 3, n. 2, jul./dez. 2001.

KLIMOVSKY, Gregorio. Las desventuras del conocimiento científico. Buenos Aires: A- Z, 1995.

MONZANI, Luiz Roberto. Freud: o movimento de um pensamento. Campinas: Editora da UNICAMP, 1989.

NAGEL, Thomas. El antropomorfismo de Freud. In:

Otras mentes. Barcelona: Gedisa, 2000.

SOLOMON. A teoria Neurológica da Mente em Freud. In: WOLLHEIM, Richard. (org.). Freud. Rio de Janeiro, RJ: Artenova, 1976. (Uma Coletânea de Ensaios Críticos).

STUART MILL, John. Système de logique déductive et inductive. Traduzido por Louis Peisse. 6. ed. Québec: Chicoutimi, 2002. Disponível em: <http://www.uqac.uquebec.ca/zone30/ classiquesdessciencessociales/ indexhtml>

Recebido em/ Received in: 25/01/2005 Aprovado em/ Approved in: 23/02/2005

Revista de Filosofia, Curitiba, v. 17 n.20, p. 11-23, jan./jun. 2005. 